\title{
The Association Between the Uncoupling Protein-1 Gene A-3826G Polymorphism and High-density Lipoprotein Cholesterol in A General Japanese Population: A Consideration of the Obesity Status
}

\author{
Kazuhiko Kotania, b, d, Shinji Fujiwara ${ }^{a}$, Kokoro Tsuzaki ${ }^{a}$, Yoshiko Sano ${ }^{a}$, \\ Narumi Nagaic, Toshiyuki Yamada ${ }^{b}$, Naoki Sakane ${ }^{a}$
}

\begin{abstract}
Background: Limited studies have shown inconsistent data about the association between the uncoupling protein 1 (UCP1) gene A$3826 \mathrm{G}$ polymorphism and high-density lipoprotein (HDL) cholesterol levels. The present study investigated the association between the A-3826G polymorphism and low HDL-cholesterolemia in nonobese and obese subjects.
\end{abstract}

Methods: Anthropometric and biochemical factors, in addition to genotyping by an allele-specific DNA assay, were measured in 294 community-dwelling Japanese subjects (male/female: 127/167, mean age: 65 years). Obesity was defined as a body mass index $(\mathrm{BMI}) \geq 25 \mathrm{~kg} / \mathrm{m}^{2}$, and low HDL-cholesterolemia was defined as $<$ $1.04 \mathrm{mmol} / \mathrm{L}$ of HDL-cholesterol.

Results: The subjects with the G/G genotype $(n=27)$ showed a significantly higher prevalence of low HDL-cholesterolemia (37\%) than those with the $\mathrm{A} / \mathrm{A}+\mathrm{A} / \mathrm{G}$ genotype (13\%) in the obese group $(\mathrm{n}=102)$. There was a non-significant difference in the prevalence of low HDL-cholesterolemia between subjects with the G/G genotype $(\mathrm{n}=45,13 \%)$ and with the $\mathrm{A} / \mathrm{A}+\mathrm{A} / \mathrm{G}$ genotype $(15 \%)$ in the non-obese group $(n=192)$. A multivariate-adjusted logistic regression analysis of the presence of low HDL-cholesterolemia revealed that carrying the $\mathrm{G} / \mathrm{G}$ genotype was an independent and significant factor positively associated with low HDL-cholesterolemia [odds

\section{Manuscript accepted for publication October 31, 2011}

${ }^{a}$ Division of Preventive Medicine, Clinical Research Institute, National Hospital Organization Kyoto Medical Center, Kyoto, Japan

${ }^{\mathrm{b}}$ Department of Clinical Laboratory Medicine, Jichi Medical

University, Shimotsuke-Tochigi, Japan

${ }^{c}$ Department of Food Science and Nutrition, University of Hyogo,

Hyogo, Japan

${ }^{\mathrm{d}}$ Corresponding author: Kazuhiko Kotani, MD, PhD, Division of Preventive

Medicine, Clinical Research Institute, National Hospital Organization Kyoto Medical Center, 1 - 1 Fukakusa Mukaihata-cho, Fushimi-ku, Kyoto, 612-8555, Japan. Email: kazukotani@jichi.ac.jp

doi:10.4021/jocmr738w ratio (OR): $6.85,95 \%$ confidence interval $(\mathrm{CI}): 1.65-28.49]$ in the obese group, while carrying the $\mathrm{G} / \mathrm{G}$ genotype exhibited a non-significant but reduced OR, by one-half, for low HDL-cholesterolemia (OR: 0.51, 95\% CI: 0.13-1.96) in the non-obese group.

Conclusions: The obesity status could have opposing impacts on the relationship between the G/G genotype and low HDL-cholesterolemia, providing insight into the need to consider the obesity levels when studying the association between the UCP-1 gene A$3826 \mathrm{G}$ polymorphism and HDL-cholesterol.

Keywords: Obesity; Body mass index; HDL-C; Atherosclerotic risk

\section{Introduction}

Obesity is a global health problem due to its epidemic proportions and the detrimental consequences associated with obesity [1, 2]. Uncoupling protein 1 (UCP1) is a mitochondrial component and a proton transporter, which uncouples oxidative metabolism from ATP synthesis, and dissipates energy through heat production [3, 4]. UCP1 plays important roles in energy homeostasis, and UCP1 gene polymorphisms have been implicated in the pathogenesis of obesity and related metabolic disorders, including lipid disorders [3, 4]. An A-3826G polymorphism within the promoter region of the UCP-1 gene is a candidate gene polymorphic site related to these disorders [5].

The blood levels of high-density lipoprotein (HDL) cholesterol (HDL-C) are a major atherosclerotic risk marker $[6,7]$. The HDL-C concentrations are generally determined by the interplay of environmental and genetic factors [7]. Few human studies have directly focused on the relationship between the UCP-1 gene A-3826G polymorphism and HDL-C levels, but inconsistent data on this relationship have been reported in several cross-sectional association studies [8-15]. Although carrying the $\mathrm{G}$ allele or $\mathrm{G} / \mathrm{G}$ genotype was reportedly associated with lower HDL-C levels $[9,11,13]$, we found no association between the A-3826G polymorphism and HDL-C levels $[8,10,12$, 
Table 1. The Clinical Characteristics of Subjects Based on the Genotypes of the Uncoupling Protein-1 Gene A-3826G Polymorphism in the Non-obese and Obese Groups

\begin{tabular}{|c|c|c|c|c|c|c|}
\hline \multirow{2}{*}{ Genotype } & \multicolumn{3}{|c|}{ Non-obese } & \multicolumn{3}{|c|}{ Obese } \\
\hline & $\mathbf{A} / \mathbf{A}+\mathbf{A} / \mathbf{G}$ & G/G & P value & $\mathbf{A} / \mathbf{A}+\mathbf{A} / \mathbf{G}$ & G/G & Pvalue \\
\hline Subject number (n) & 147 & 45 & - & 75 & 27 & - \\
\hline Age (years) & $66 \pm 12$ & $66 \pm 13$ & 0.98 & $63 \pm 14$ & $62 \pm 15$ & 0.72 \\
\hline Male (n) & $67(46 \%)$ & $21(47 \%)$ & 0.90 & $30(40 \%)$ & $9(33 \%)$ & 0.55 \\
\hline Current smoker (n) & $23(16 \%)$ & $8(18 \%)$ & 0.73 & $9(12 \%)$ & $3(11 \%)$ & 0.90 \\
\hline BMI $\left(\mathrm{kg} / \mathrm{m}^{2}\right)$ & $22.2 \pm 2.0$ & $22.3 \pm 1.9$ & 0.64 & $27.1 \pm 1.9$ & $27.4 \pm 2.3$ & 0.48 \\
\hline $\mathrm{SBP}(\mathrm{mmHg})$ & $139 \pm 20$ & $135 \pm 19$ & 0.26 & $139 \pm 21$ & $138 \pm 17$ & 0.92 \\
\hline DBP (mmHg) & $77 \pm 10$ & $74 \pm 10$ & 0.08 & $78 \pm 13$ & $80 \pm 13$ & 0.52 \\
\hline T-chol (mmol/L) & $4.85 \pm 0.87$ & $4.94 \pm 1.13$ & 0.69 & $4.86 \pm 0.85$ & $4.72 \pm 0.97$ & 0.48 \\
\hline HDL-C (mmol/L) & $1.44 \pm 0.38$ & $1.43 \pm 0.38$ & 0.94 & $1.39 \pm 0.36$ & $1.20 \pm 0.30$ & $0.01^{*}$ \\
\hline LHDLC (n) & $22(15 \%)$ & $6(13 \%)$ & 0.79 & $9(13 \%)$ & $10(37 \%)$ & $<0.01^{*}$ \\
\hline $\mathrm{TG}(\mathrm{mmol} / \mathrm{L})$ & $0.98(0.75-1.23)$ & $0.98(0.76-1.52)$ & 0.24 & $1.05(0.84-1.51)$ & $1.15(0.86-1.39)$ & 0.86 \\
\hline HbAlc (\%) & $5.6 \pm 1.3$ & $5.6 \pm 1.3$ & 0.97 & $5.6 \pm 0.7$ & $5.5 \pm 0.6$ & 0.85 \\
\hline
\end{tabular}

BMI: body mass index; SBP: systolic blood pressure; DBP: diastolic blood pressure; T-chol: total cholesterol; HDL-C: high-density lipoprotein cholesterol; LHDLC: low high-density lipoprotein cholesterolemia; TG: triglycerides; HbA1c: hemoglobin A1c. The data are expressed as the means \pm standard deviation, medians (interquartile range) or subject number (\%). Differences in data between the genotype-based groups were examined by the unpaired t-test or $X^{2}$-test within each group of non-obese and obese subjects. The TG values were log-transformed because of their skewed distribution in the analysis. Significant level: *: P<0.05.

14] as well as a possibly protective association of the $\mathrm{G} / \mathrm{G}$ genotype with low HDL-cholesterolemia [15]. The UCP-1 expression is regulated by the condition of the individual, including the extent of obesity, and carrying the G allele is related to a reduced UCP-1 expression in obese subjects [9]. Therefore, the inconsistencies reported between studies on the association between the A-3826G polymorphism and HDL-C levels [8-15] may be, at least in part, explained by the difference in the studied populations, such as differences in the composition of obese and non-obese subjects. In fact, we noted that all of the studies showing that carrying the $\mathrm{G}$ allele or $\mathrm{G} / \mathrm{G}$ genotype was significantly associated with lower HDL-C levels were in obese populations \{i.e., 42-47 $\mathrm{kg} / \mathrm{m}^{2}$ [9], $33 \mathrm{~kg} / \mathrm{m}^{2}$ [11], and $34 \mathrm{~kg} / \mathrm{m}^{2}$ [13] for the mean body mass index (BMI) $\}$ except one study (mean BMI 45 $\mathrm{kg} / \mathrm{m}^{2}$ ) [8], while studies showing no association between the A-3826G polymorphism and HDL-C $[10,12,14]$ and carrying the $\mathrm{G} / \mathrm{G}$ genotype as a protective factor for low HDL-cholesterolemia [15] were for relatively non-obese populations \{i.e., mean BMI $25.5 \mathrm{~kg} / \mathrm{m}^{2}$ (in Caucasians) [10], $22 \mathrm{~kg} / \mathrm{m}^{2}$ [12], $22 \mathrm{~kg} / \mathrm{m}^{2}$ [14], and 22-23 kg/m² [15]\}. Based on this background information, the present study aimed to compare the association between the UCP-1 gene A-3826G polymorphism and low HDL-cholesterolemia in a general Japanese population by analyzing subject-groups separated according to their obesity status.

\section{Methods}

This cross-sectional association study included a total of 294 community-dwelling Japanese subjects [127 males and 167 females, mean age $65 \pm 13$ (SD) years], recruited from community-based health check-ups conducted in the Mima area of Japan. The study was approved by the institutional ethics committee and each subject gave informed consent. The subjects who were basically asymptomatic and not taking any medication were eligible. Excluded were subjects who suffered from any acute inflammatory disease, or had a clinical history of cardiovascular, thyroid, malignant, severe hepatic or renal diseases.

Smoking habits were determined as a current or nonsmoker through a self-reported questionnaire. In addition to the BMI, calculated as the body weight $(\mathrm{kg})$ divided by the square of the height (m), the systolic blood pressure (SBP) and diastolic blood pressure (DBP) were measured in the seated subject's right arm using a mercury sphygmomanometer. Blood was sampled after an overnight fast. The serum 
Table 2. The Results of the Multivariate-adjusted Logistic Regression Analysis of Factors Associated With Low Highdensity Lipoprotein Cholesterolemia in the Non-obese and Obese Groups

\begin{tabular}{llllll}
\hline \multirow{2}{*}{ Factor } & \multicolumn{2}{c}{ Non-obese } & & \multicolumn{2}{c}{ Obese } \\
\cline { 2 - 3 } Age (years) & OR (95\% CI) & P value & & OR (95\% CI) & Pvalue \\
Gender (male) & $1.04(0.98-1.09)$ & 0.19 & & $1.04(0.98-1.11)$ & 0.22 \\
Current smoking (presence) & $1.05(0.86-10.78)$ & 0.08 & & $0.95(0.19-4.75)$ & 0.95 \\
BMI (kg/m $)$ & $1.72(0.43-6.83)$ & 0.44 & & $6.51(0.71-59.9)$ & 0.10 \\
SBP (mmHg) & $0.94(0.70-1.27)$ & 0.69 & & $1.53(1.05-2.21)$ & $0.03^{*}$ \\
DBP (mmHg) & $0.98(0.94-1.02)$ & 0.32 & & $0.94(0.89-0.99)$ & $0.03^{*}$ \\
T-chol (mmol/L) & $1.02(0.94-1.10)$ & 0.63 & & $1.06(0.98-1.16)$ & 0.15 \\
TG (mmol/L) & $0.95(0.93-0.97)$ & $<0.01^{*}$ & & $0.95(0.92-0.99)$ & $<0.01^{*}$ \\
HbAlc (\%) & $1.03(1.02-1.05)$ & $<0.01^{*}$ & & $1.02(1.01-1.03)$ & $<0.01^{*}$ \\
G/G genotype (presence) & $1.14(0.79-1.65)$ & 0.49 & & $1.67(0.51-5.46)$ & 0.40 \\
\hline
\end{tabular}

OR: odds ratio; Cl: confidence interval; BMI: body mass index; SBP: systolic blood pressure; DBP: diastolic blood pressure; Tchol: total cholesterol; HDL-C: high-density lipoprotein cholesterol; TG: triglycerides; HbA1c: hemoglobin A1c. All the listed factors, including the $G / G$ genotype of the uncoupling protein-1 gene $A-3826 G$ polymorphism (reference: the $A / A+A / G$ genotypes), were entered into the multivariate-adjusted logistic regression analysis models. Significant level: *: $P<0.05$.

total cholesterol (T-chol), triglycerides (TG) and HDL-C levels were enzymatically measured. Hemoglobin A1c (HbA1c) levels were measured using a high performance liquid chromatography method. Genomic DNA was extracted from the subject's buccal mucosa cells obtained using cytobrushes, and genotypes were determined by an intercalatermediated fluorescent allele-specific PCR method using specific primers, as described previously [8].

The data were presented as the means \pm standard deviation (SD) or the medians plus interquartile range. The genotype and allele frequencies for Hardy-Weinberg equilibrium were examined using the $\chi^{2}$-test. Differences between the genotype-based groups were compared using either the unpaired t-test, one way ANOVA (with a multi-comparison test), or $\chi^{2}$-test (with a residual analysis) in each group of non-obese and obese subjects. When the two groups by genotype were compared, we divided subjects into the $\mathrm{A} / \mathrm{A}+\mathrm{A} / \mathrm{G}$ genotype group and the $\mathrm{G} / \mathrm{G}$ genotype group according to the earlier study [15]. The TG values were log-transformed because of their skewed distribution in this analysis. A multivariate logistic regression analysis on the presence of low HDL-cholesterolemia, adjusted for all the measured factors including the $\mathrm{G} / \mathrm{G}$ genotype (reference: the $\mathrm{A} / \mathrm{A}+\mathrm{A} / \mathrm{G}$ genotype), was performed to observe whether the genotype was associated with low HDL-cholesterolemia in each group of non-obese and obese subjects. Obesity was defined as a BMI $\geq 25 \mathrm{~kg} / \mathrm{m}^{2}$ according to the clinical guideline of the Japan society for the study of obesity [16], and low HDL-cholesterolemia was defined as HDL-C $<1.04 \mathrm{mmol} / \mathrm{L}$ according to the clinical guideline of the Japan Atherosclerosis Society [17]. A P-value $<0.05$ was considered to be significant.

\section{Results}

Overall, the distributed number of A/A, A/G and G/G genotypes was 91 (31\%), $131(45 \%)$ and $72(24 \%)$, respectively, among all subjects $(n=294)$. The frequency of the G-allele was $47 \%$. This frequency was similar to earlier Japanese reports $[12,14,15]$. These frequencies were in Hardy-Weinberg equilibrium $\left(\chi^{2}=1.64, \mathrm{P}=0.45\right)$. In the non-obese group $(n=192)$, the subject number of $A / A, A / G$ and $G / G$ genotypes was $59(31 \%), 88(46 \%)$ and $45(23 \%)$, while in the obese group $(n=102)$, the subject number of $A / A, A / G$ and $\mathrm{G} / \mathrm{G}$ genotypes was 32 (31\%), 43 (42\%) and 27 (27\%), respectively. There was no significant difference in the genotype distribution between the non-obese and obese groups $(\mathrm{P}=0.79)$.

When the clinical characteristics of subjects were compared between the respective genotype carriers, significant differences in HDL-C levels (A/A genotype: $1.37 \pm 0.41 \mathrm{mmol} / \mathrm{L}, \mathrm{A} / \mathrm{G}: 1.42 \pm 0.31 \mathrm{mmol} / \mathrm{L}, \mathrm{G} / \mathrm{G}: 1.20 \pm$ $0.30 \mathrm{mmol} / \mathrm{L} ; \mathrm{F}=3.54, \mathrm{P}=0.03$ ) and the prevalence of low HDL-cholesterolemia (A/A genotype: 5 subjects, 16\%, A/G: 
4 subjects, $9 \%$, G/G: 10 subjects, $37 \% ; \mathrm{F}=0.461, \mathrm{P}=0.01$ ) were observed in the obese group. There were significant differences in HDL-C levels between the $\mathrm{A} / \mathrm{G}$ genotype and $\mathrm{G} / \mathrm{G}$ genotype carriers $(\mathrm{P}=0.03)$ and the prevalence of low HDL-cholesterolemia between the $\mathrm{A} / \mathrm{G}$ genotype and $\mathrm{G} / \mathrm{G}$ genotype carriers $(\mathrm{P}=0.01)$ in this group. The other measured factors did not show any significant differences between the respective genotype carriers in the non-obese and obese groups (data not shown).

The clinical characteristics of the two groups by genotype (the $\mathrm{A} / \mathrm{A}+\mathrm{A} / \mathrm{G}$ genotype group versus the $\mathrm{G} / \mathrm{G}$ genotype group) are listed in each group of non-obese and obese subjects in Table 1. In the obese group, the $\mathrm{G} / \mathrm{G}$ genotype carriers had significantly lower HDL-C levels and a significantly higher prevalence of low HDL-cholesterolemia than the $\mathrm{A} / \mathrm{A}+\mathrm{A} / \mathrm{G}$ genotype carriers. The other measured factors did not show any significant differences between the two groups by genotype in the non-obese and obese groups.

Subsequently, the results of the multivariate-adjusted logistic regression analysis of the presence of low HDLcholesterolemia are shown in Table 2. In the obese group, the analysis revealed that carrying the $\mathrm{G} / \mathrm{G}$ genotype, as well as the BMI and TG, was an independent and significant positive factor associated with low HDL-cholesterolemia, while the SBP and T-chol showed an independent and significant inverse association with low HDL-cholesterolemia. In the non-obese group, the same analysis revealed that the TG showed an independent and significant positive association and the T-chol showed an independent and significant inverse association with low HDL-cholesterolemia, while carrying the $\mathrm{G} / \mathrm{G}$ genotype exhibited a non-significant but reduced (by one-half) odds ratio (OR) for the association with the presence of low HDL-cholesterolemia.

\section{Discussion}

The present study showed that the G/G genotype of the UCP-1 gene A-3826G polymorphism was an independent and significant factor positively associated with low HDL-cholesterolemia in the obese group, while the $\mathrm{G} / \mathrm{G}$ genotype was a relatively protective factor associated with low HDL-cholesterolemia in the non-obese group. Even though the results of the OR for the G/G genotype on low HDL-cholesterolemia in the non-obese group did not reach a statistically significant level, the impact of the reduction of the OR (by one-half) with regard to low HDLcholesterolemia should not be ignored. The results of the obese group are similar with the previous studies $[9,11$, 13], and the results of the non-obese group likely confirm the earlier study [15]. Blood levels of HDL-C are a major atherosclerotic risk marker, and the association between HDL-C metabolism and genetic factors remains to be explored. It is therefore important to note that there may be an opposite trend for the association between the UCP-1 gene A-3826G polymorphism and low HDL-cholesterolemia based on the obesity status of subjects. This may provide a possible explanation for the inconsistent data shown for this association in the previous studies [8-15] and it may also provide further understanding of the different roles of the UCP-1 gene A-3826G polymorphism under obese and nonobese conditions.

The precise mechanisms underlying the present findings are unclear. UCP-1 is a mitochondrial protein, potentially associated with energy homeostasis $[3,4]$. UCP-1 is basically expressed in brown adipose tissue, and recent studies have shown that adult humans possess metabolically active brown adipose tissue [18-20]. Changes in the oxidation of free fatty acids in the mitochondria can alter the blood levels of lipids through tissue cholesterol transport; thus, this pathway to control blood lipids may be affected by genetic polymorphisms such as the UCP-1 gene A-3826G polymorphism [13]. The UCP-1 expression is regulated by the extent of obesity, and the $\mathrm{G}$ allele has been reported to be related to a reduction of the expression of the gene in an obese population [9]. This may be one reason for the present finding that the $\mathrm{G} / \mathrm{G}$ genotype is positively associated with low HDL-cholesterolemia in obese subjects. On the other hand, the UCP-1 expression remains to be incompletely examined in non-obese populations including lean subjects [9]. There may be a difference in the UCP-1 expression and the role of the A-3826G polymorphism in regulating the levels of blood lipids between obese and non-obese subject-populations. Such a difference may partially account for the present study findings.

In the present study, the TG (in the non-obese and obese groups) and BMI (in the obese group) were factors that were positively associated with low HDL-cholesterolemia. These associations have been well-recognized [21]. In addition, that the T-chol (in the non-obese and obese groups) was a factor inversely associated with low HDL-cholesterolemia is plausible, because HDL-C participates in regulating the T-chol levels. Although the SBP (in the obese group) was a factor that was inversely associated with low HDL-cholesterolemia, this appeared to be paradoxical, because low HDL-cholesterolemia is an atherosclerotic risk factor. The reason for this relationship was not determined, so further studies, including the SBP-related confounders, will be required.

The present study had a few limitations. The sample size was relatively small, and there was not a very high prevalence of low HDL-cholesterolemia. This might have lead to the non-significance of the association between the $\mathrm{G} / \mathrm{G}$ genotype and low-HDL-cholesterolemia in the non-obese group. The cross-sectional design of the study did not fully allow for determination of the cause-and-effect relationship between factors. Moreover, although there have been some reports showing the association between HDL-C levels and 
genetic variations of the other types of uncoupling proteins such as UCP-2 and UCP-3 [22, 23], no data on such types of uncoupling proteins were available in this study. Additional studies with larger populations, prospective designs and various genetic polymorphisms are needed.

In summary, carrying the $\mathrm{G} / \mathrm{G}$ genotype of the UCP-1 gene A-3826G polymorphism was an independent and significant factor positively associated with low HDL-cholesterolemia in obese subjects, and in contrast, carrying the $\mathrm{G} / \mathrm{G}$ genotype was a relatively protective factor associated with low HDL-cholesterolemia in non-obese subjects. The present findings may provide an explanation for the inconsistent data obtained in the previous studies (of populations with a different status of obesity) regarding the association between the UCP-1 gene A-3826G polymorphism and HDL-C, and may provide a hint about the different roles of the UCP-1 gene A-3826G polymorphism under obese and non-obese conditions. Further studies are warranted to confirm these results and to clarify the biological mechanism(s) responsible for the observed association.

\section{Acknowledgements}

This study was supported in part by a Grant-in-Aid for the Foundation for the Development of the Community, Japan.

\section{Conflicts of Interest}

There are no conflicts of interest to declare.

\section{References}

1. James WP. WHO recognition of the global obesity epidemic. Int J Obes (Lond). 2008;32 Suppl 7:S120-126.

2. Hetherington MM, Cecil JE. Gene-environment interactions in obesity. Forum Nutr. 2010;63:195-203.

3. Garruti G, Ricquier D. Analysis of uncoupling protein and its mRNA in adipose tissue deposits of adult humans. Int J Obes Relat Metab Disord. 1992;16(5):383-390.

4. Del Mar Gonzalez-Barroso M, Ricquier D, CassardDoulcier AM. The human uncoupling protein-1 gene (UCP1): present status and perspectives in obesity research. Obes Rev. 2000;1(2):61-72.

5. Arner P. Obesity--a genetic disease of adipose tissue? $\mathrm{Br}$ J Nutr. 2000;83 Suppl 1:S9-16.

6. Bruckert E, Hansel B. HDL-c is a powerful lipid predictor of cardiovascular diseases. Int $\mathrm{J}$ Clin Pract. 2007;61(11):1905-1913.

7. Sviridov D, Nestel PJ. Genetic factors affecting HDL levels, structure, metabolism and function. Curr Opin Lipidol. 2007;18(2):157-163.
8. Clement K, Ruiz J, Cassard-Doulcier AM, Bouillaud F, Ricquier D, Basdevant A, Guy-Grand B, et al. Additive effect of $A-->G(-3826)$ variant of the uncoupling protein gene and the Trp64Arg mutation of the beta 3-adrenergic receptor gene on weight gain in morbid obesity. Int J Obes Relat Metab Disord. 1996;20(12):1062-1066.

9. Esterbauer H, Oberkofler H, Liu YM, Breban D, Hell E, Krempler F, Patsch W. Uncoupling protein-1 mRNA expression in obese human subjects: the role of sequence variations at the uncoupling protein-1 gene locus. J Lipid Res. 1998;39(4):834-844.

10. Schaffler A, Palitzsch KD, Watzlawek E, Drobnik W, Schwer H, Scholmerich J, Schmitz G. Frequency and significance of the A-->G (-3826) polymorphism in the promoter of the gene for uncoupling protein-1 with regard to metabolic parameters and adipocyte transcription factor binding in a large population-based Caucasian cohort. Eur J Clin Invest. 1999;29(9):770-779.

11. Kiec-Wilk B, Wybranska I, Malczewska-Malec M, Leszczynska-Golabek L, Partyka L, Niedbal S, Jabrocka A, et al. Correlation of the $-3826 \mathrm{~A}>\mathrm{G}$ polymorphism in the promoter of the uncoupling protein 1 gene with obesity and metabolic disorders in obese families from southern Poland. J Physiol Pharmacol. 2002;53(3):477490.

12. Matsushita H, Kurabayashi T, Tomita M, Kato N, Tanaka K. Effects of uncoupling protein 1 and beta3-adrenergic receptor gene polymorphisms on body size and serum lipid concentrations in Japanese women. Maturitas. 2003;45(1):39-45.

13. Oh HH, Kim KS, Choi SM, Yang HS, Yoon Y. The effects of uncoupling protein-1 genotype on lipoprotein cholesterol level in Korean obese subjects. Metabolism. 2004;53(8):1054-1059.

14. Nakano T, Shinka T, Sei M, Sato Y, Umeno M, Sakamoto K, Nomura I, et al. A/G heterozygote of the A-3826G polymorphism in the UCP-1 gene has higher BMI than A/A and $\mathrm{G} / \mathrm{G}$ homozygote in young Japanese males. J Med Invest. 2006;53(3-4):218-222.

15. Kotani K, Sakane N, Saiga K, Adachi S, Shimohiro H, $\mathrm{Mu} \mathrm{H}$, Kurozawa Y. Relationship between A-3826G polymorphism in the promoter of the uncoupling protein-1 gene and high-density lipoprotein cholesterol in Japanese individuals: a cross-sectional study. Arch Med Res. 2008;39(1):142-146.

16. New criteria for 'obesity disease' in Japan. Circ J. 2002;66(11):987-992.

17. Teramoto T, Sasaki J, Ueshima H, Egusa G, Kinoshita M, Shimamoto K, Daida H, et al. Diagnostic criteria for dyslipidemia. Executive summary of Japan Atherosclerosis Society (JAS) guideline for diagnosis and prevention of atherosclerotic cardiovascular diseases for Japanese. J Atheroscler Thromb. 2007;14(4):155-158.

18. van Marken Lichtenbelt WD, Vanhommerig JW, Smul- 
ders NM, Drossaerts JM, Kemerink GJ, Bouvy ND, Schrauwen P, et al. Cold-activated brown adipose tissue in healthy men. N Engl J Med. 2009;360(15):15001508.

19. Cypess AM, Lehman S, Williams G, Tal I, Rodman D, Goldfine AB, Kuo FC, et al. Identification and importance of brown adipose tissue in adult humans. N Engl J Med. 2009;360(15):1509-1517.

20. Virtanen KA, Lidell ME, Orava J, Heglind M, Westergren R, Niemi T, Taittonen M, et al. Functional brown adipose tissue in healthy adults. N Engl J Med. 2009;360(15):1518-1525.
21. Vinik AI. The metabolic basis of atherogenic dyslipidemia. Clin Cornerstone. 2005;7(2-3):27-35.

22. Cha MH, Kim IC, Kim KS, Kang BK, Choi SM, Yoon Y. Association of UCP2 and UCP3 gene polymorphisms with serum high-density lipoprotein cholesterol among Korean women. Metabolism. 2007;56(6):806-813.

23. Hamada T, Kotani K, Fujiwara S, Sano Y, Domichi M, Tsuzaki K, Sakane N. The common $-55 \mathrm{C} / \mathrm{T}$ polymorphism in the promoter region of the uncoupling protein 3 gene reduces prevalence of obesity and elevates serum high-density lipoprotein cholesterol levels in the general Japanese population. Metabolism. 2008;57(3):410-415. 